\title{
Research on Social Responsibility Cultivation Model of Vocational College Students
}

\author{
Guang-Mei LIN ${ }^{1, a}$, Kun BAI ${ }^{2, b, ~}$, Zhen KONG ${ }^{1, c}$, \\ ${ }^{1}$ Beijing Information Technology College, No. 5, Fangyuanxilu, Chaoyang District, Beijing, China \\ ${ }^{2}$ University of International Relations, No. 12, Poshangcun, Haidian District, Beijing, China \\ aLingm@bitc.edu.cn, ${ }^{\mathrm{b}}$ Baikun@uir.edu.cn, ${ }^{\mathrm{C}}$ Kongz@bitc.edu.cn \\ *Corresponding author
}

Keywords: Students; Vocational College; Social responsibility; Training mode; Innovation.

\begin{abstract}
Effective social responsibility training model is one of the important ways to realize the goal of high-quality talent education. Therefore, cultivation model of vocational students' social responsibility becomes a hot issue drawing attention from some experts and scholars. Based on investigations in colleges and enterprises in Beijing, the research team firstly sums up the definition of vocational students' social responsibility, and secondly concludes the cultivation model in six dimensions. The above research leads to framework description as so-called 6133 model of the training objectives, contents, methods and evaluation for students' improvement.
\end{abstract}

\section{Introduction}

Based on the analysis of contemporary Chinese college students' social responsibility connotation, the basic theory and the current meaningful training methods of college students' social responsibility in China are: to put the socialism core value system as the important content of college students ' ideological education; to strengthen the social practice, to adhere to the unification of action-awareness; and to establish the "holy trinity" education system. An emphasis on "learning by doing", through the practice of different modules, improves their occupational activities and establishes a correct attitude towards life. Research was done by visiting counselors and deans in vocational colleges, and by questioning human resources department managers about the present situation of social responsibility and the enterprise demands. Joint efforts by schools and families are the main ways to cure.

\section{Six Training Objectives}

Social responsibility is a raging concept in the modern world. It is the responsibility of the students towards the society. Since they use society's resources they must provide something to the society in return. The basic objective of social responsibility in these days is to maximize the person's overall impact on the society and stakeholders. A growing number of students feel that social responsibility is not just another form of indirect expense but is important for protecting the goodwill and reputation, as well as for increasing competitiveness. Research on vocational students' social responsibility is under the theoretic guidance of political education, ethics and psychology. 6133 model briefly describes the six dimensions of training objectives as followed.

\section{The Self-Responsibility}

One is able to correct cognition of self-ability, to make life planning for self-development or long-term and clear goals. That is the rational way to cherish one's own health and life. Thereafter, he or she has strong adaptability and ability to resist frustrations. As a result, there must be a goal of belief and willpower, filled by optimistic attitude toward life, to constantly practice and finish the plan on time on the life stage. 


\section{The Family Sense}

Vocational students should have correct consciousness of family responsibility. Only being inspired by family members can the students succeed in their careers. Emotional care for family members is essential for a potential employee to develop mutual responsibility and self-reliance ability. Students ought to respect their parents for providing economic sources, understanding the main responsibility and treating the parents gratefully.

\section{Corporate Responsibility}

Students learn the concepts such as cooperation, compromise and tolerance. They abide by the discipline in group activities. They understand that the individual will obey collective interests.

\section{Caring Others}

Students learn to respect others, to care about others, to be ready to help others. They keep promise in accordance with perspective-taking. They understand others, so as to be adapted to the harmonious community.

\section{Environmental Responsibility}

Students should have the good social public morality, take an active part in social labor, and maintain public order. Being kind to nature and life is also the important element of establishing environment sense to save resources by the concept of low carbon life.

\section{National Responsibility}

Vocational students should be loyal to the motherland, support the leadership of the Communist Party, maintain the dignity of the country and unity, and safeguard national unity. Besides, they ought to be concerned about the state affairs, the country's prosperity. Their sense of mission and goals are consistent with the Chinese Dream.

\section{Tripartite Joint Education Methods}

According to the different education content, requirements and hierarchical culture, the 6 dimensions need to be realized by joint methods step by step. For the freshmen, it is important to adopt cognitive education and practice education. For the junior, it is important to adopt practice to strengthen the education on professional ethics. For the senior, it is extremely useful to improve social sense of responsibility. The training derives from the integration and sharing of advantageous resources such as political theory courses, campus cultural activities and other lectures. The trainers come from teachers and counselors.

\section{Trinity Education Cognition and Practice}

The cultivation of the self-responsibility focused on the life planning. The students in Grade One can quickly absorb knowledge on the Morality and Law course to set up a blueprint for the future. More and more ideal cognition, behavior and guidance will come into being. Combined with the right outlook on life, values and the world, life, guide, students step down on the correct path towards life. The students should put the theory into practice through large-scale activities, such as school drama.

\section{Strengthening the Professional Ethics}

Volunteer service is quite instructive for establishing social responsibility. High-quality activity needs careful design to inspire the students' enthusiasm to do social work in their spare time. Experience in the real situation, such as sports, science and technology festival, is another way to provide necessary training. And the national defense education, military training and blood donation causes the student to further strengthen the social responsibility in the practice training. Sports strengthen students' sense of cherishing the body health and achieving the goal with a firm faith and determination. 


\section{Right Course Content}

Courses on the economy, ethics and law strengthen students' sense of social responsibility. Social responsibility education is definitely the transmission of knowledge and skills, to formulate specific activities surrounding social responsibility education goals. So, in a professional situation, students cultivate the collective sense of responsibility and team cooperation. The professional ethics make students give up the interests of the poor temptation. Nurturance to others, the society and the environment will be the result of this kind of right course content. Counselors provide interpretation about important employment and entrepreneurship policies, encouraging the students lay foundation for entering the society or emerging in the enterprise culture. Lectures on career orientation, career planning, and career choice guide the students to have a correct understanding about themselves accurately. After the course, a student says, "I am a professional person, I am responsible for professional career." The introduction of practical training in the real situational is more suitable for vocational students.

\section{Competence-Oriented Integration}

Establish competence-oriented integration of theory and practice is the reasonable training roadmap. The method is more suitable for the needs of the vocational students' characteristics, because strengthening moral education is the best way to turn college students' social responsibility into self-aware behavior. Competency features include both explicit and implicit. The former includes knowledge and skills, and the latter includes practical ability training with dominant components. Through motivation, quality, attitude, values, self-image and social role, training has a series of activities. According to the research data, nuclear family is the universal family type in China and takes up $68.15 \%$ in all of the family types. Along with the nuclear family is the only-child's education. Only-child vocational college students who have superiority in their grow-up are over-concerned, self-centered and require more from their parents, teachers and the society. They have stronger sense of their rights and weaker sense of responsibility. At the same time, contemporary college students don't have much social experience, it makes them have one-sided and partial understanding of the world. Most of them can't recognize the mutual dependence and mutual-shouldering of responsibility between people. The social function of education is to help people to be useful in society, which means helping them to cultivate their personality closer to social character, and accord their desires with the role and duty. If students correctly understand the relation between individual with society, they will realize their responsibility in near future. Daniel Bell, American socialist, stated that every society should set up a system with certain meanings which people can use to demonstrate the collection from themselves to the world. These meanings regulate a set of purpose, like myth or ceremony, explaining the character of common experience, or rebuilding nature through personal magic or technology. The loss of these meanings in these fields would cause a puzzled situation, not affordable, so people are forced to pursuit new meanings to avoid everything left from turning into empty. Therefore, on one hand, in the process of moral education, we need to conquer the situation with less education guidance.

\section{Summary}

Cultivation theory examines the long-term effects of moral education. The more time teachers spend training on campus, the more likely their students are to believe social responsibility portrayed in schools. Under this umbrella, perceptions of the world are heavily influenced by the images and ideological messages transmitted through popular media. Internet might be another wave on the social responsibility cultivation model of vocational college students. Teaching is to help students to enhance the ideological and political and legal qualities and key professional competence, so effective ways to improve teaching determine the teaching content and students ideological status, in accordance with the professional competence requirements, divided into 
teaching modules to develop the module syllabus, integration modules textbook, carefully organize the teaching reform and evaluation methods. Vocational students' social responsibility 6133 training model makes a tripartite linkage, the integration of theory and practice of cultivation path, in view of the different layers of the vocational students to learn in three different grades by three training modes. In a word, through the definite target, vocational students' social responsibility education will be conscientiously implemented by the social responsibility actions.

\section{Acknowledgement}

This research was financially supported by Beijing Education Science "12th five-year" Plan Project Research on Social Responsibility Cultivation Model of Vocational College Students in Beijing DFB13123, by CPC Beijing Municipal Education Committee Project Research on Teaching Model of Morality and Law in Vocational Colleges BJSZ2015ZC235 hosted by Guangmei Lin, and by Beijing Information Technology College Research Subject XY-YN-14-201516.

\section{References}

[1] Wei HONG, Youth Navigation. Scientific and Technical Documentation, Beijing, 2013

[2] Peter F. Drucker, Innovation and Entrepreneurship: Practice and Principles, Harper Business, New York, 2006, pp.155-179

[3] Daniel Bell, Culture Contradiction of Capitalism. SDX Joint Publishing Company, Beijing, 1989 